\title{
HPLC Monitoring of Acid Catalyzed Conversion of 7-Ethyltryptophol to Methyl Ester of Etodolac
}

\author{
Iva Habinovec, ${ }^{1}$ Željka Car, ${ }^{1, *}$ Rosana Ribić, ${ }^{1}$ Nives Galić,,${ }^{1, \#}$ Predrag Novak, ${ }^{1}$ Ernest Meštrović, ${ }^{2}$ Srđanka Tomić ${ }^{1}$
}

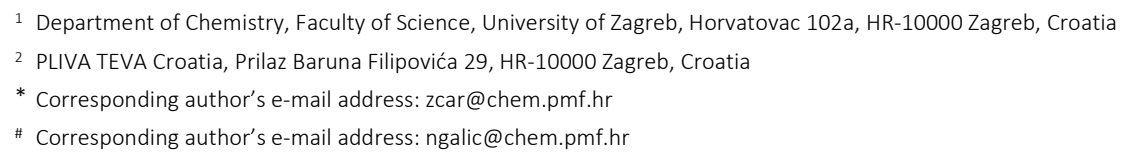

RECEIVED: October 7, 2016 * REVISED: April 12, 2017 * ACCEPTED: May 1, 2017

Proceeding of the 28th Math/Chem/Comp Conference, June 20-25, 2016, Dubrovnik, Croatia

\begin{abstract}
Small scale experimental model for the preparation of methyl ester of etodolac, the key intermediate in the synthesis of nonsteroidal drug etodolac, is thoroughly investigated in order to define the key parameters needed for its large scale production. Oxa-Pictet-Spengler reaction of 7-ethyltryptophol and methyl 3-oxopentanoate with inorganic acids as catalysts was monitored over time using HPLC method with UV detection. HPLC method for the simultaneous determination of 7-ethyltryptophol and the product was developed first. The conversion of 7-ethyltryptophol to etodolac precursor was performed using different molar equivalents of acid (1-5 with respect to the $\beta$-ketoester) and starting 7-ethyltryptophol of different degrees of purity. Kinetic profiles and optimal reaction times were in each case defined and key parameters selected.
\end{abstract}

Keywords: HPLC method, kinetic profile, Oxa-Pictet-Spengler reaction, etodolac methyl ester.

\section{INTRODUCTION}

$\mathbf{T}$ O ensure controlled and reproducible production of pharmaceutical compounds, secure knowledge and model for troubleshooting during life cycle of a product as well as to embed quality into pharmaceutical products to ultimately protect patient safety are the main goals of systematic quality-by-design (QbD) approach ${ }^{[1,2]}$. Hence, small scale experimental models should be thoroughly investigated first for every active pharmaceutical ingredient. This often includes the understanding of critical steps in reaction mechanisms, the study of kinetic profiles for every conversion, impurity content analysis, etc. High performance liquid chromatography (HPLC) is by far the most important tool used in the assessment of these parameters. The HPLC methods for etodolac, a nonsteroidal drug (NSAID) used in humans and domestic animals due to its analgesic, antipyretic and antiinflammatory effects, ${ }^{[3]}$ described in literature are mostly used for its determination in tablets ${ }^{[4,5]}$, human plasma ${ }^{[3,6,7]}$ and in river waters ${ }^{[8]}$. To the best of our knowledge there are no reports that describe the HPLC monitoring of conversion of 7-ethyltryptophol (7-ET) to etodolac methyl ester (EME), the main precursor in etodolac synthesis, over time on any scale. Furthermore, there are no methods described for the simultaneous determination of 7-ethyltryptophol and etodolac methyl ester.

The synthetic procedures for the preparation of etodolac and its precursors were presented in the past by several authors ${ }^{[0-14]}$. The key intermediate in the etodolac synthesis is its alkyl ester which is obtained by the oxa-Pictet-Spengler reaction (Scheme 1) promoted by different Brönsted and Lewis acids. ${ }^{[13]}$ Since Lewis acids are often expensive and difficult to manage in productions on a larger scale, inorganic mineral acids $\left(\mathrm{HCl}, \mathrm{HBr}, \mathrm{H}_{2} \mathrm{SO}_{4}, \mathrm{H}_{3} \mathrm{PO}_{4}\right)$ are preferred. ${ }^{[12]}$ For example, in the report by Vigano and Colombo ${ }^{[12]}$ the reaction of 7-ethyltryptophol with methyl 3-oxopentanoate, conducted in an apolar solvent (toluene), the amount of $\mathrm{HCl}$ or $\mathrm{H}_{2} \mathrm{SO}_{4}$ added was in a molar ratio from 0.5 to 5 with respect to 7-ethyltryptophol.

The syntheses of tryptophol and its derivatives are often characterized by low to moderate yields and / or low 

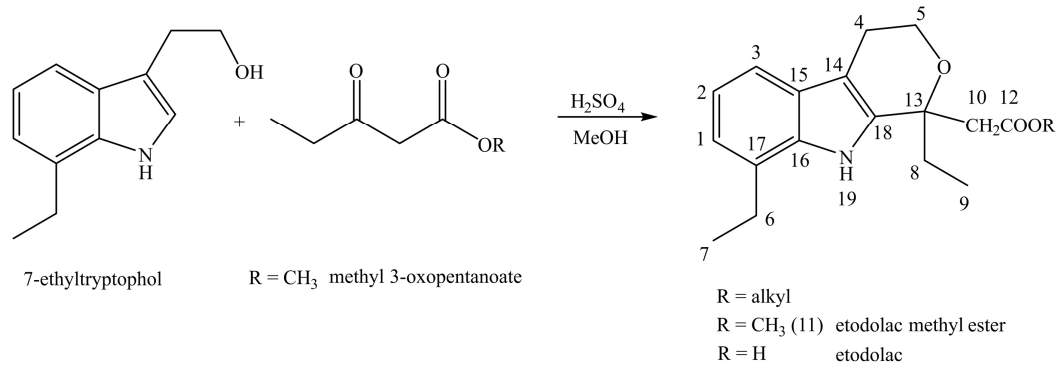

Scheme 1. Preparation of etodolac methyl ester by oxa-Pictet-Spengler reaction in methanol using sulfuric acid as a catalyst. ${ }^{[15]}$

purity of the product. ${ }^{[16]}$ As a consequence, 7-ethyltryptophol is accessible on the market in various degrees of purity, with some variation in price. The preparation of etodolac methyl ester by oxa-Pictet-Spengler reaction starting from 7-ethyltryptophol with purity ranging from 79 to $95 \%$ is reported in several patents. ${ }^{[13,14]}$ Therefore, we have developed the HPLC method to monitor the oxa-Pictet-Spengler conversion of 7-ethyltryptophol to etodolac methyl ester over time. Based on the obtained kinetic profiles the optimal reaction conditions and parameters for the synthesis of etodolac methyl ester were selected.

\section{EXPERIMETAL}

\section{HPLC Method Development and Optimization}

Agilent 1220 Infinity LC with variable wavelength detector (VWD), an autosampler and thermostated column compartment was used for HPLC analysis. UV spectra were recorded on the Varian Cary 3 UV-Vis spectrophotometer. 7Ethyltryptophol ( $99.4 \%$ purity) and etodolac methyl ester standards were supplied from PLIVA TAPI Croatia. Chromatographic columns used for the method optimization were as follows: Waters Symmetry Shield TM RP 18 (250 mm $\times 4.6$ $\mathrm{mm} ; 5 \mu \mathrm{m})$, Waters XBridge ${ }^{\mathrm{TM}}$ Phenyl $(150 \mathrm{~mm} \times 4.6 \mathrm{~mm}$; $3.5 \mu \mathrm{m})$ and Phenomenex ${ }^{\mathrm{R}}$ Luna $\mathrm{NH}_{2}(250 \mathrm{~mm} \times 4.6 \mathrm{~mm} ; 5$ $\mu \mathrm{m})$. Elution was performed using different mobile phases: $\psi$ (acetonitrile, acetate buffer $\mathrm{pH} 4)=55: 45, \psi$ (acetonitrile, ultra-pure water) $=85: 15, \psi$ (acetonitrile, ultra-pure water) $=65: 35, \psi$ (acetonitrile, ultra-pure water) $=55: 45$, $\psi$ (methanol, phosphate buffer $\mathrm{pH} 7)=55: 45$.

Phosphate buffer $\left(0.05 \mathrm{~mol} \mathrm{~L}^{-1}, \mathrm{pH}\right.$ 7) was prepared by dissolving $6.805 \mathrm{~g}$ of potassium dihydrogen phosphate in $1 \mathrm{~L}$ of mili-Q water. $\mathrm{pH}$ of the solution was adjusted to 7 with $2 \mathrm{~mol} \mathrm{~L}^{-1} \mathrm{NaOH}$. Buffer solution was filtered under reduced pressure through $0.22 \mu \mathrm{m}$ filter prior to HPLC analysis.

Preparation of acetate buffer $(\mathrm{pH} 4)$ was performed by dissolving $10 \mathrm{~mL}$ of acetic acid in $2 \mathrm{~L}$ of mili- $\mathrm{Q}$ water $(\varphi=$ $0.5 \%$ ). $\mathrm{pH}$ was adjusted to 4 with $2 \mathrm{~mol} \mathrm{~L}^{-1} \mathrm{NaOH}$.
The results of HPLC analysis on different columns are given in Table 1. Final chromatographic conditions used in order to obtain kinetic profiles were: Waters Symmetry Shield ${ }^{\mathrm{TM}}$ RP $18(250 \mathrm{~mm} \times 4.6 \mathrm{~mm} ; 5 \mu \mathrm{m})$ column, $\psi$ (acetonitrile, ultra-pure water) $=55: 45$, as mobile phase, flow rate $1.6 \mathrm{~mL} \mathrm{~min}{ }^{-1}$, injection volume $7 \mu \mathrm{L}$, column temperature $25^{\circ} \mathrm{C}$, detection wavelength $225 \mathrm{~nm}$ and runtime $15 \mathrm{~min}$.

\section{General Synthetic Procedure for the Conversion of 7-Ethyltryptophol, Sampling and HPLC Analysis}

All solvents (HPLC grade) were puchased from SigmaAldrich Corp. and all reagents were supplied by PLIVA TAPI Croatia. The experiments with 7-ethyltryptophol of $79 \%$ purity were performed as follows: $5 \mathrm{~g}$ of the starting compound ( $20.9 \mathrm{mmol}$ of pure) was dissolved in $12 \mathrm{~mL}$ of methanol. The solution was cooled to $15{ }^{\circ} \mathrm{C}$ and $2.89 \mathrm{~mL}$ of methyl 3-oxopentanoate $(23 \mathrm{mmol})$ was added next. Aliquots of inorganic acid ( 95 to $97 \%$ sulfuric and $37 \%$ hydrochloric acid; molar equivalents with respect to $\beta$-ketoester for each reaction are listed in Table 2 ) were added gradually within $75 \mathrm{~min}$ at 0 to $5{ }^{\circ} \mathrm{C}$ (ice bath) while stirring. Then reaction mixtures were heated at $30^{\circ} \mathrm{C}$ until the end of sampling. After cooling at 4 to $8{ }^{\circ} \mathrm{C}$ for $1 \mathrm{~h}$ the product was filtered off, recrystallized from methanol and vacuum dried (average yields of isolated product are listed in Table 2).

In the analogous experimental procedure with $5 \mathrm{~g}$ of 7-ethyltryptophol of $98 \%$ purity $(25.9 \mathrm{mmol})$ methanol (12 $\mathrm{mL}$ ) was also used as solvent and the volume of methyl 3oxopentanoate was $3.61 \mathrm{~mL}$ ( $28.6 \mathrm{mmol})$. Molar equivalents of sulfuric acid with respect to $\beta$-ketoester for each reaction and average yields are listed in Table 2 .

The structure of etodolac methyl ester (Scheme 1) was confirmed by ${ }^{1} \mathrm{H},{ }^{13} \mathrm{C}$ and ${ }^{1} \mathrm{H}-{ }^{13} \mathrm{C} \mathrm{HMBC}$ NMR spectroscopy using Bruker Avance III HD $400 \mathrm{MHz}$ spectrometer, $\mathrm{CDCl}_{3}$ as solvent and tetramethylsilane (TMS) as internal standard. NMR data for isolated etodolac methyl esters were all analogous and were as follows: ${ }^{1} \mathrm{H}$ NMR $(\delta / \mathrm{ppm})$ 9.05 (br s, $1 \mathrm{H}, \mathrm{H} 19), 7.36$ (dd, $1 \mathrm{H}, J=1.2 \mathrm{~Hz}, J=7.5 \mathrm{~Hz}, \mathrm{H} 1$ ), 7.08-6.99 (m, $2 \mathrm{H}, \mathrm{H} 2, \mathrm{H} 3), 4.08-3.89(\mathrm{~m}, 2 \mathrm{H}, \mathrm{H} 5), 3.71$ (s, 3 
Table 1. Retention times for 7-ethyltryptophol (7-ET) and etodolac methyl ester (EME) under different chromatographic conditions.

\begin{tabular}{|c|c|c|c|c|c|c|}
\hline \multirow[b]{4}{*}{ Mobile phase } & & & & & & \\
\hline & \multicolumn{6}{|c|}{ Column } \\
\hline & \multicolumn{2}{|c|}{$\begin{array}{c}\text { C18 } \\
t_{\mathrm{R}} / \min \end{array}$} & \multicolumn{2}{|c|}{$\begin{array}{l}\text { Phenyl } \\
t_{\mathrm{R}} / \mathrm{min}\end{array}$} & \multicolumn{2}{|c|}{$\begin{array}{c}\mathrm{NH}_{2} \\
t_{\mathrm{R}} / \min \end{array}$} \\
\hline & 7-ET & EME & 7-ET & EME & 7-ET & EME \\
\hline$\psi($ acetonitrile, acetate buffer $\mathrm{pH}=4)=55: 45$ & 2.983 & 9.695 & 2.639 & 6.783 & 1.363 & 1.508 \\
\hline$\psi($ acetonitrile, ultra-pure water $)=55: 45$ & 2.996 & 9.791 & 2.627 & 6.767 & 1.362 & 1.513 \\
\hline$\psi($ methanol, phosphate buffer $\mathrm{pH}=7)=55: 45$ & 7.589 & 38.394 & 6.889 & 31.314 & 2.271 & $-(\mathrm{a})$ \\
\hline$\psi$ (acetonitrile, ultra-pure water) $=85: 15$ & 1.886 & 2.621 & 1.155 & 1.432 & 1.579 & 1.760 \\
\hline$\psi$ (acetonitrile, ultra-pure water) $=65: 35$ & 2.373 & 5.448 & 1.353 & 2.472 & 1.410 & 1.547 \\
\hline
\end{tabular}

(a) No separation from 7-ethyltryptophol was achieved

$\mathrm{H}, \mathrm{H} 11), 3.05-2.70$ (m, $6 \mathrm{H}, \mathrm{H} 10, \mathrm{H} 6, \mathrm{H} 4), 2.23-1.94$ (m, 2 $\mathrm{H}, \mathrm{H} 8), 1.37(\mathrm{t}, 3 \mathrm{H}, J=7.6 \mathrm{~Hz}, \mathrm{H} 7), 0.85(\mathrm{t}, 3 \mathrm{H}, J=7.4 \mathrm{~Hz}$, H9). ${ }^{13} \mathrm{C}$ NMR ( $\delta$ / ppm) 173.24 (C12), 135.88, 134.43 (C16, C18), 126.58, 126.13 (C15, C17), 120.36, 119.56, 115.92 (C1, C2, C3), 108.39 (C14), 74.58 (C13), 60.61 (C5), 51.95 (C11), 42.78 (C10), 30.64 (C8), 24.18 (C6), 22.38 (C4), 13.74 (C7), 7.56 (C9).

The sampling procedure for all described experiments was the same and was performed in regular time periods as indicated in Figures 4, S1-S5. A 10- $\mu \mathrm{L}$ aliquot of the reaction mixture was taken in different time periods and dissolved in $990 \mu \mathrm{L}$ of HPLC mobile phase $\psi$ (acetonitrile, ultra-pure water) $=55: 45$. A $10-\mu \mathrm{L}$ aliquot of the resulting solution was additionally diluted by dissolving in $490 \mu \mathrm{L}$ of HPLC mobile phase. The resulting samples were then analyzed twice by the developed HPLC method. The first aliquot ( $t=0 \mathrm{~min}$ ) was taken before the addition of inorganic acid.

\section{RESULTS AND DISCUSSION}

\section{HPLC Monitoring of Conversion of 7-Ethyltryptophol to Etodolac Methyl Ester Over Time}

In this work we selected $79 \%$ and $98 \%$ pure starting compound and explored the influence of impurities on the time needed for the conversion of the indole derivative to etodolac precursor ( $\mathrm{R}=\mathrm{CH}_{3}$, Scheme 1). Based on the proposed $^{[17]}$ three-step mechanism of intramolecular oxaPictet-Spengler reaction we chose to vary the molar equivalents of inorganic acid with respect to $\beta$-ketoester, methyl 3-oxopentanoate. Since the product, etodolac methyl ester, precipitates from the reaction mixture, the decrease in 7-ethyltryptophol concentration was monitored over time.

In order to get kinetic profiles of reactions catalyzed with different molar ratios of sulfuric and hydrochloric acid, HPLC method with UV detection was developed first. UV spectra of reactants and the product were recorded to define detection wavelength (Figure 1). Based on the results obtained, $225 \mathrm{~nm}$ wavelength was chosen for HPLC analysis as the optimal one.

The best chromatographic separation was achieved

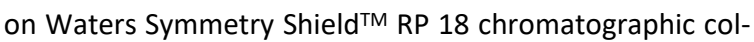
umn $(250 \mathrm{~mm} \times 4.6 \mathrm{~mm} ; 5 \mu \mathrm{m}$ ) using $\psi$ (acetonitrile, ultrapure water) $=55: 45$ as mobile phase. As an example, the representative chromatogram of the mixture of 7-ethyltryptophol and etodolac methyl ester acquired under the optimal conditions is given in Figure 2.

In the continuation of the work, the limit of detection (LOD) as well as the limit of quantification (LOQ) were determined based on signal to noise ratio of $3: 1$ and 10 : 1 , respectively. LOD for 7-ethyltryptophol amounted to 8 $\mathrm{ng} \mathrm{mL}-1$ and $25 \mathrm{ng} \mathrm{mL}^{-1}$ for etodolac methyl ester, while LOQ was $26 \mathrm{ng} \mathrm{mL}^{-1}$ for 7-ethyltryptophol and $83 \mathrm{ng} \mathrm{mL}^{-1}$ for etodolac methyl ester.

Linearity of detector response was checked in the concentration range from below LOQ to $150 \mu \mathrm{g} \mathrm{mL}^{-1}$. Regression analysis of chromatographic data showed that detector response was linear in the concentration range from

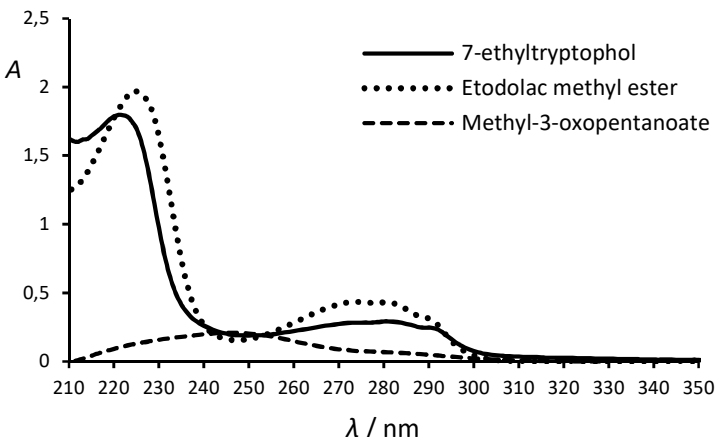

Figure 1. UV spectra of 7-ethyltryptophol, methyl-3-oxopentanoate and etodolac methyl ester in acetonitrile. Concentration of each compound amounted to $5 \times 10^{-5} \mathrm{~mol} \mathrm{~L}^{-1}$. 


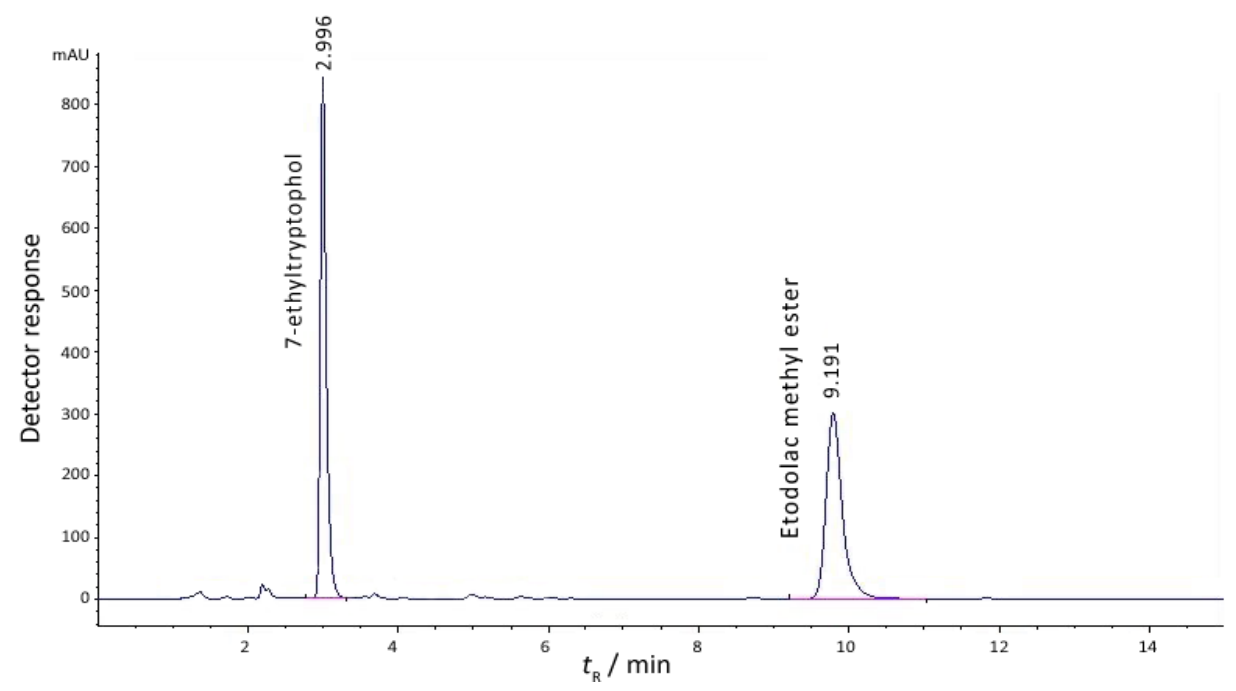

Figure 2. Chromatogram of the standard mixture of 7-ethyltryptophol and etodolac methyl ester. $\gamma$ (7-ethyltryptophol) = $\gamma$ (etodolac methyl ester $)=150 \mu \mathrm{gL}^{-1}$.

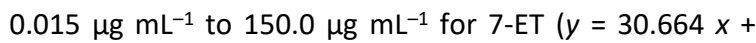
21.145, $\left.r^{2}=0.9994\right)$ and from $0.0498 \mu \mathrm{g} \mathrm{mL}^{-1}$ to $150.0 \mu \mathrm{g}$ $\mathrm{mL}^{-1}$ for EME $\left(y=22.399 x+18.794, r^{2}=0.9995\right)$. Based on the linear range and LOQ determined, the conditions for the reaction monitoring were selected.

In experiments carried out with $p$-toluenesulfonic acid as catalyst, the presence of dehydrating agents, such as activated molecular sieves or anhydrous $\mathrm{Na}_{2} \mathrm{SO}_{4}$, which aided water elimination in the second step of the reaction mechanism, were important in achieving high yields. ${ }^{[17]}$ Reactions carried out with sulfuric acid, which is known dehydrating agent as well, resulted in shorter reactions times and higher yields compared to those experiments performed with hydrochloric acid. High water content in concentrated $\mathrm{HCl}$ also affects reaction times needed for the conversion. Thus, 5 molar equivalents of hydrochloric acid were needed for those experiments to be even comparable to the reactions carried out with 1 molar equivalent of sulfuric acid in terms of reaction times and yields (Table 2, Figures S1 and S4).

In the case of the indole derivative of lower purity time needed for reaction completion was found to be

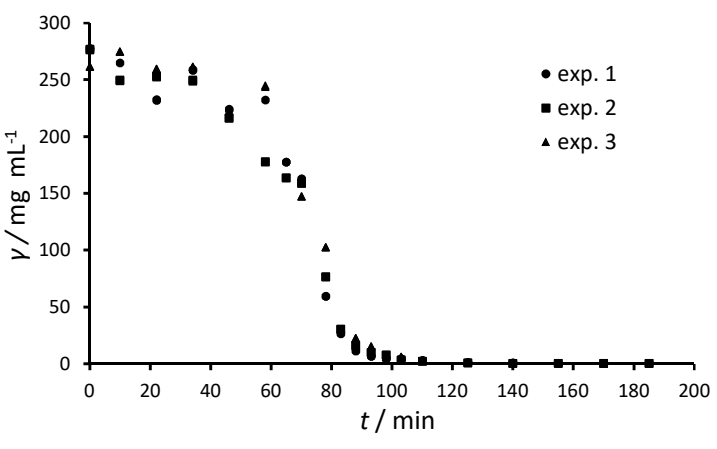

Figure 3. Conversion of $98 \%$ 7-ethyltryptophol with 2 equivalents of $\mathrm{H}_{2} \mathrm{SO}_{4}$.

strongly dependent of the molar equivalents of the sulfuric acid added (160-180 min and 120-130 min for 2 and 3 molar equivalents, respectively). On the other hand, the reaction times needed for the completion of the synthesis with the 7-ethyltryptophol of $98 \%$ purity and the same molar equivalents of acid were much shorter and approximately in the same time range $(90-110 \mathrm{~min}$, Table 2, Figures 3, S2, S3 and S5).

Table 2. Summary results for the conversion of 7-ET to EME over time with respect to the purity of the starting compound and equivalents of inorganic acid added.

\begin{tabular}{lccc|c|cc} 
& \multicolumn{4}{c}{$79 \% 7-\mathrm{ET}$} & \multicolumn{2}{c}{$98 \% 7-\mathrm{ET}$} \\
\cline { 2 - 7 } & \multicolumn{3}{c}{$\mathrm{H}_{2} \mathrm{SO}_{4}$} & $\mathrm{HCl}$ & \multicolumn{2}{c}{$\mathrm{H}_{2} \mathrm{SO}_{4}$} \\
\hline equivalent(s) & 1 & 2 & 3 & 5 & 3 \\
reaction time / $\mathrm{min}$ & $575-585$ & $160-180$ & $120-130$ & $595-605$ & $90-110$ & $90-110$ \\
average yields of isolated products / \% & 81 & 86 & 90 & 77 & 97 & 98 \\
\hline
\end{tabular}




\section{CONCLUSIONS}

Small scale experimental model for the synthesis of etodolac precursor is thoroughly investigated in order to obtain critical parameters needed for its controlled larger scale preparation. In the development of the HPLC method for the simultaneous monitoring of unreacted 7-ethyltryptophol and the product over time, several columns with different stationary phases were used, and elution was performed with three different solvent mixtures in an isocratic mode. Finally, RP 18 column was selected with acetonitrile and water mobile phase. Conversion of 7-ethyltryptophol to etodolac methyl ester was explored in view of the purity of the starting compound and the amount of acid used.

Acknowledgment. We wish to thank European Regional Development Fund and Croatian state budget for the support of this work as a part of the project "Development of new methodology for the control of drug preparation processes - Met4Pharm".

Supplementary Information. Supporting information to the paper is attached to the electronic version of the article at: http://dx.doi.org/10.5562/cca3016.

\section{REFERENCES}

[1] N. P. Nadpara, R. V. Thumar, V. N. Kalola, P. B. Patel, Int. J. Pharm. Sci. Rev. Res. 2012, 17, 20.
[2] F. G. Vogt, A. S. Kord, J. Pharm. Sci. 2011, 100, 797.

[3] H.-S. Lee, I.-M. Kang, H.-W. Lee, J.-H. Seo, J.-H. Ryu, S.-J. Choi, M.-J. Lee, S.-Y. Jeong, Y.-W. Cho, K.-T. Lee, J. Chromatogr. B 2008, 863, 158.

[4] V. Siva Rama Krishna, S. Belemkar, R. N. Tiwari, Int. J. PharmTech Res. 2014, 6, 775.

[5] O. A. Saleh, A. A. El-Azzouny, H. Y. Aboul-Enein, A. M. Badawey, M. S. Rashed, J. Liq. Chrom. Relat. Tech. 2009, 32, 2584.

[6] C. de Miranda Silva, A. Rocha, E. Tozatto, L. M. da Silva, E. A. Donadi, V. L. Lanchote, J. Pharm. Biomed. Anal. 2016, 20, 120.

[7] I. I. Hewala, M. S. Moneeb, H. A. Elmongy, A.-A. M. Wahbi, Talanta 2014, 130, 506.

[8] K. Hoshina, S. Horiyama, H. Matsunaga, J. Haginaka, J. Pharm. Biomed. Anal. 2011, 55, 916.

[9] C. A. Demerson, L. G. Humber, T. A. Dobson, I. L. Jirkovsky, US patent 3,939,178., Feb. 17, 1976.

[10] C. A. Demerson, L. G. Humber, US Patent 4,585,877, Apr. 29, 1986.

[11] G. Vincenzo, P. Franco, US Patent 5,599,946, Feb. 4, 1997.

[12] E. Vigano, P. Colombo, US Patent 6,066,741, May 23, 2000.

[13] E. L. Larghi, T. S. Kaufman, Eur. J. Org. Chem. 2011, 5195.

[14] L. Zhu, C. Wang, CN 101077872 B, Jun. 21, 2007.

[15] Y. Jinzong Jiang, CN 1740174, Aug. 23, 2005.

[16] M. C. Sekharayya, G. V. Narayana, S. Nigam, G. Madhusudhan, Ind. J. Chem. 2012, 51B, 1763.

[17] E. L. Larghi, T. S. Kaufman, Synthesis 2006, 0187. 